\title{
"This angle that we talked about": learning how to weld in interaction
}

\author{
Nina Kilbrink $^{1}$ (D) $\cdot$ Stig-Börje Asplund ${ }^{1}$ (i)
}

Accepted: 10 December 2018 / Published online: 18 December 2018

(c) The Author(s) 2018

\begin{abstract}
The specific focus of this article is how critical aspects of the object of learning to weld are made relevant in interaction between a vocational teacher and a student in the learning processes of welding as part of a Swedish upper-secondary technical vocational education programme. By intertwining variation theory with a conversation analytical approach, our analysis shows that the teaching focus alternates between the process as a whole and details about the welding process, and how the relation between the critical aspects are negotiated in the teaching situations. Furthermore, the teacher and the student together build up a common resource of experiences to which they can relate the parts and the whole, and the teaching becomes increasingly subject specific as the teacher and student build up more common experiences. The approach used in this article sheds light on the complexity of learning to weld, and also facilitates an understanding of welding as an object of learning as such.
\end{abstract}

Keywords Learning content · Welding · Variation theory · Conversation analysis · Interaction $\cdot$ Technical vocational education

\section{Introduction}

The learning content in programme specific subjects in technical vocational education is often handled in the interaction between student and teacher. However, there are few studies focusing on how different learning content is being taught and learned in the interaction between student and teacher (Asplund and Kilbrink 2018). Today, there is also a lack of studies focusing on teaching and learning in technical vocational education. Hence, we know very little about the learning processes involved in this field of learning (cf. Berglund 2009; Kilbrink 2013, 2018; Pahl 2014). The specificity of teaching and learning in vocational subject areas and learning technical content has been highlighted in different studies, and the centrality of handicraft, practical experience and physical work has been

Nina Kilbrink

nina.kilbrink@kau.se

Stig-Börje Asplund

stig-borje.asplund@kau.se

1 Department of Educational Studies, Karlstad University, Karlstad 651 88, Sweden 
emphasised (cf. Bjurulf 2008; Björkholm 2015; Kilbrink 2013; von Schantz Lundgren et al. 2013). Furthermore, Björkholm (2015) and Kilbrink (2018) argue for the importance of studying technical objects of learning in order to learn more about teaching and learning in technical subjects.

To meet this need of research, this article describes and analyses two observed teaching situations, during which a teacher and student interact on the programme specific object of learning to weld in technical vocational education. The specific focus of this article is on the learning processes involved when an upper-secondary student and a vocational teacher engage in welding as part of a Swedish upper-secondary technical vocational education programme providing training for a career in plumbing. How to weld was chosen as the object of learning in this study while it is one of the central objects of learning for prospective plumbers. Previous studies show that it can be a fruitful way of studying both the what-aspect and the how-aspect of learning by combining the two theories variation theory and conversation analysis (Asplund and Kilbrink 2018; Emanuelsson and Sahlström 2008). Critical aspects of the object of learning can be highlighted and negotiated in the interaction between teacher and student, and what is possible to learn is depending on the dynamic interaction during the action of welding in the vocational classroom. This was one of the results we concluded in our previous research, where we put the interaction in the foreground to examine the learning process of how to weld (Asplund and Kilbrink 2018). In the present study, however, we put the learning content at foreground to study what critical aspects of the enacted object of learning to weld are highlighted in the interaction.

In a previous study, Filliettaz (2011) gives examples on how verbal interaction can be a pedagogical resource when apprentices learn how to weld by experienced workers at workplaces and in another study, Chan and Leijten (2012) focus on verbal interaction in relation to feedback and peer learning when welding. Furthermore, Sakai et al. (2014) investigate the interaction in relation to relevant objects when welding. However, the vocational teaching and learning at school as well as the specific focus on the learning content when teachers and students interact is not included in those previous studies. Therefore, this study can complement the previous studies with a more content related and subject specific didactical approach on teaching and learning to weld. Thereby, this article moves the research on teaching and learning to weld in school contexts one step further. Based on these conditions, the research question in this study is the following:

Towards which critical aspects of the object of learning how to weld do a student and teacher orient in their interaction, and how are these aspects made relevant?

This article describes how critical aspects of the object of learning are made relevant in the interaction between a teacher and a student during two teaching situations in the process of learning a programme specific object of learning in technical vocational education. How the two perspectives are used in this study is described below.

\section{Theoretical and methodological framework}

In this study, learning is regarded as a process that includes both what is being learned and how learning is done in interaction during the actual teaching situation (for further elaboration, see Asplund and Kilbrink 2018; Emanuelsson and Sahlström 2008; Marton and Tsui 2004; Sahlström 2011). To reach both these aspects of the learning process, two theoretical and methodological frameworks are used-the variation theory on learning and conversation analysis. Previous studies using variation theory have mainly focused on content 
in teaching and learning, without paying attention to the interaction between teachers and learners (cf. Bjurulf 2008; Kilbrink et al. 2014; von Schantz Lundgren et al. 2013). However, social interaction can influence how content is highlighted in the learning situation, and by studying how the object of learning is enacted during interaction, we can get a deeper understanding of learning processes concerning both what is being learned and how this learning is done in interaction. This is done by integrating variation theory analysis (VTA) with conversation analysis (CA) of the interaction on a specific object of learning in a teaching situation (Asplund and Kilbrink 2018). By combining the VTA and CA perspectives, we aim to reach broader knowledge of both the what- and the how-aspects of learning a specific object of learning in technical vocational education.

\section{VTA: variation theory analysis}

Variation theory is a learning theory focusing on the content of learning and learning is described as a changed way of seeing or experiencing something (cf. Marton and Booth 1997; Marton and Tsui 2004). In variation theory, the emphasis is on this something, the learning content as the object of learning (OoL). The OoL can be described as intended (what the teacher planned), enacted (what was possible to learn in the teaching/learning situation) or lived (what the students actually learned) (Marton and Tsui 2004). The space of learning is also a shared space (Tsui 2004) in which teachers and students interact. Furthermore, interaction between the teacher and the learner influences the enacted OoL (Asplund and Kilbrink 2018). In this study, we focus solely on the enacted OoL and what is possible to learn in the interaction between a vocational student and his teacher.

In teaching, some things are foregrounded while other things remain more or less in the background (Lo 2012; Marton and Booth 1997). In a teaching situation, it is important to foreground the aspects that are to be learned, the critical aspects, and to make sure that the same things are in the foreground for both teacher and student (cf. Lo and Chik 2016). What is in the foreground and what is in the background can change during the situation, depending on the interaction between teacher and student (cf. Asplund and Kilbrink 2018). Critical aspects are those aspects that are important to understand in order to learn an OoL. Critical aspects can adopt different values, which can vary or remain constant (invariant). For example, if colour is a critical aspect of an OoL, it can adopt the different values red, blue, green, etc. Which critical aspects to focus on in teaching can differ between different groups of students (Marton and Tsui 2004). Critical aspects can be highlighted in teaching by using different patterns of variation. Variation theory identifies four such patterns: fusion, which means that all critical aspects are present at the same time; separation, through which one critical aspect of the OoL is highlighted and varied, while others are kept invariant; contrast, which entails comparing the varied critical aspect to something it is not (red is not blue); and finally, generalisation, which means that the critical aspect is highlighted by showing different appearances of the critical aspect (there are different shades of red) (cf. ibid.). Lo and Chik (2016) also describe two horizons of fusion: one concerns how the parts and the critical aspects of the OoL relate to each other (internal horizon of fusion) and the other how the OoL as a whole relates to its environment (external horizon of fusion). In order to deepen knowledge of the OoL, learning needs to expand from the internal horizon of fusion to relate to the external horizon of fusion. In this analysis based on variation theory (compare Asplund and Kilbrink 2018), we focus on the critical aspects of the OoL that emerge in interaction and the patterns of variation that are used. We call this Variation Theory Analysis (VTA). 


\section{CA: conversation analysis}

This article is also based on an understanding of teaching and learning as constituted in interaction, and we use the methodological tools provided by conversation analysis in order to analyse and describe how aspects of teaching and learning take shape through the participants' orientations in the situated activity of learning how to weld.

Conversation analysis (henceforth CA) deals with the methodical ways in which action is constituted through participants' simultaneous use of different semiotic resources in face-to-face interaction (Hutchby and Wooffitt 2008; Schegloff 2007). A fundamental principle in CA is that both meaning and understanding are "established, sustained and changed in and through the coordinated interaction of people" (Sahlström 2009, p. 103) and the interaction between people and artefacts in specific social and cultural contexts (Drew and Heritage 2006; Goodwin 2000; Schegloff 2007).

In contemporary $\mathrm{CA}$, using and analysing video recordings provide important ways of investigating how conversation participants carry out courses of collaborative actions and how they show their interpretation and understanding of each other's actions (Goodwin 2000; Hutchby and Wooffitt 2008; Schegloff 1996, 2006).

In identifying which actions the participants themselves orient to as relevant at a specific moments in the interaction, and to show this in a convincing way to other researchers, CA research has developed a method that is referred to as a "proof procedure" (cf. Heath 1997, p. 187; Sacks, Schegloff and Jefferson 1974, pp. 728-729), by taking the viewpoint of the participants. The way in which previous turns and actions have been interpreted becomes visible when analysing how participants show their understanding of previous turns and actions in the way the next action is accomplished. Thus, the method involves the use of the participants' demonstrated understanding of each other's actions and thereby provides material for analytic explication. In doing this, video recordings are transcribed in great detail according to specific conventions (e.g. Hutchby and Wooffitt 2008; Ochs et al. 1996).

In the methodical organisation of turn-taking and sequences, not only talk but also other semiotic resources such as gazes, gestures, body movements and physical objects are seen as constitutive of and integral to the ongoing interaction. Thus, in this article the relationship between talk and embodied practices is viewed as processes that mutually contextualise one another, providing public resources for the teacher and the student to organise relevant actions which, in concert with each other, contribute to the ongoing situated activity of welding (Asplund 2016; Asplund and Kilbrink 2018; Goodwin 2000, 2006; Streeck, Goodwin and LeBaron 2011). The use of detailed representations of the interaction that has been developed within CA is in this article presented in the form of detailed transcriptions of spoken data (see transcript notations in Table 1 below for transcription conventions), as well as still images of visual phenomena in the interaction between the teacher and the student.

\section{Data material}

The data material on which the analysis is based consists of two films from a workshop lesson in a vocational programme educating prospective plumbers. A researcher filmed the interaction between a teacher and a novice welding student in two different situations. Examples from each film were chosen to be analysed in detail using VTA and 
Table 1 Transcript notations

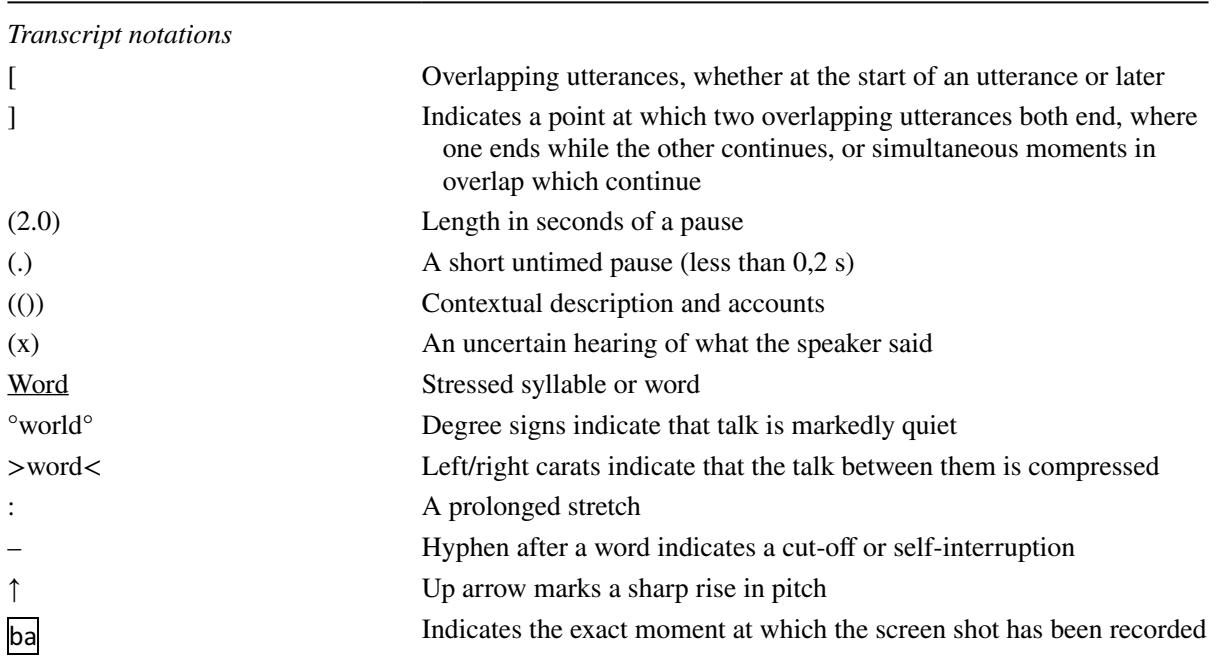

CA. Both teaching situations concern welding, but in the first situation (Situation 1) the OoL is welding on a plate, and, in the second (Situation 2), the object of learning concern welding two pipes together. The video recordings form part of a larger research project about vocational learning, and the two examples were chosen because they present teaching situations in which a teacher and a novice student interact in relation to the specific learning content to weld. The analysis focus is on which critical aspects emerge in the teaching situation and what patterns of variation are used in the interaction between the teacher and the learner. The critical aspects can be foregrounded by both the teacher and the student in the interaction (cf. Asplund and Kilbrink 2018). In the analysis presentation below, the critical aspects emerging in the interaction are highlighted in bold, and the pattern of variation used in relation to the critical aspects is shown in italics.

\section{Analysis and results}

The examples are derived from a welding workshop with welding booths in a vocational school where the teacher is interacting with a student practicing welding (see Appendix for transcript notations). This is the first time the student is welding in the school's workshop. In the following excerpt, Robin (the student, "S") has been welding on his own in front of the teacher ("T") for a short time and is then encouraged by his teacher to "rest a bit": 


\section{"Do you know what is strange!?" (Situation 1)}

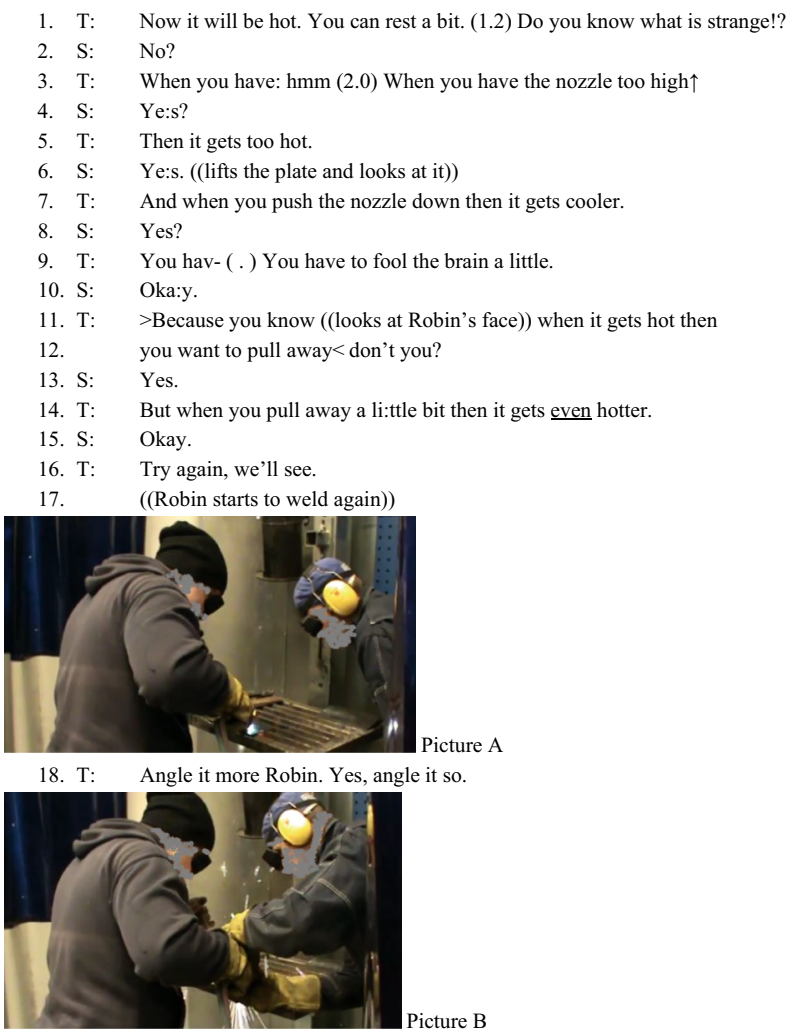

19. ((grabs Robin's right hand which is holding the nozzle, and moves the hand down 20. towards the bench at an angel from Robin's body)) Angle it like tha:t (2.3) Tha:t's 21. right.

22-25. [...

26. S: Doesn't it get very very thin here now?

27. T: ((looks at Robin)) It doesn't matter.

28. S: ((continues to weld))

29. T: Yes, like that. Good. ( . ) You need to heat more back first Robin. Turn more ba -

30. ((moves his left hand towards his body))

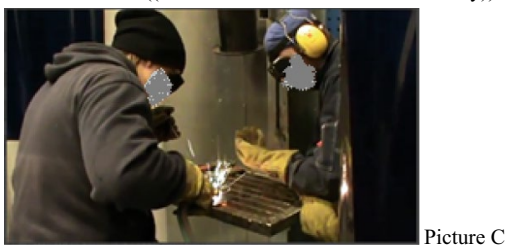

31. like that yes. And then you go forward and cut towards then you cut the with

32. the flame if you say so. Now! And then you turn around. Angle it more. Yes so! (9.0)

33. Do you think it is hard to do aro- paddle around then then just poke in it so that it

34. might attach in the middle for you or it get less attached then. (3.5) Yes so, good that

35. you: let it take time. Because it takes time to weld. 
When Robin has welded for a while, the teacher makes Robin aware that "it" will be hot and that he should rest for a while from the welding process (line 1). In this sequence, heat emerges as a critical aspect of welding in the interaction, by being singled out from other critical aspects using separation as pattern of variation. The teacher follows up his request with a rhetorical question ("Do you know what is strange, Robin?") which leads to a situation in which the teacher again is given the epistemic authority (Heritage and Raymond 2005) he is positioning himself as the more knowledgeable other who can demonstrate his skills by instructing the student how to weld. In this section he is not doing it as a role model, by showing all critical aspects by fusion, but instead he emphasises different critical aspects one by one, using separation. In the turns that follow, it is the welding nozzle's distance to the material being welded that the teacher and the student orient towards, and, according to the teacher's action, it is also made clear that the distance to the plate that they orient to, follows a"different" logic and therefore also demands a "different" way of thinking.

In lines 4 and 6 the teacher informs the student that if he holds the welding nozzle "too high" during the act of welding, it then "gets too hot". Here the heat is highlighted as a critical aspect by separation. This critical aspect is emphasised as a consequence of the distance of the welding flame to the plate, which emerges as a further critical aspect. If he would then "push the nozzle down then it gets cooler" (line 7). The teacher then follows up this statement in line 10 with the suggestion that "You have to fool the brain a little". Hence, the values that the critical aspect distance to the plate can gain are: too high, too low and something in-between that is correct, but it is not explicitly made clear what it is. The pattern of variation that appears in relation to the distance to the plate could be seen as contrasting an expected experience that the teacher highlights in line 1 ("Do you know what is strange?"), in line 9 ("You have to fool the brain a little") and in line 11-12 ("when it gets hot then you want to pull away, don't you?"). Hence, the contrast is not made into something that is happening in the actual situation, but is something that the teacher expects the student to experience. Thus, this pattern of variation requires the student to be simultaneously aware of what happens here and now, and is also something that the teacher expects him to know already.

Robin's reaction in line 10 (a somewhat cautious "oka:y") is an expression of displayed attention but also a readiness to listen further. Robin's somewhat cautious response is followed up by the teacher who continues his efforts to explain how to think when one is welding. He begins this in lines 11-12, where he positions Robin as someone who "knows" that when "it gets hot, you want to pull away". Hence, what the teacher is doing in the example is to start from what one could say is a completely normal and natural reaction: if you are confronted with a situation during which something gets too hot, the normal reaction would be to retract from the heat you are exposed to. In this specific situation, which the teacher and the student are oriented to, this means that if/when the temperature gets too high at the welding point during the welding act, the normal/natural reaction is to remove the welding nozzle and its flame from the material. The teacher makes the student aware that both he and the student already "know" this. Also, the teacher uses the expression "don't you?" when saying that "when it gets hot then you want to pull away, don't you?", which is our translation of the Swedish epistemic adverb $j u$ that underlines that what is being said is something known by the other present participants (Aijmer 1996, p. 421). Thus, the teacher's utterance is affirmed by Robin in the following turn. Then, the teacher shifts his reasoning when saying, "But when you pull away a li:ttle bit then it gets even hotter". Robin affirms this with a more distinct "okay" than he did before (line 15) and in connection with this, the teacher asks him to "try again" (line 16). The teacher's expression "try again, then we'll see" encourages the student to continue welding. In 
the act of welding, the previously separated critical aspects are now included at the same time by the variation pattern fusion.

When Robin starts welding again, the teacher leans forward towards the welding place (Picture A). Soon after this, the teacher tells the student to "angle it more" (line 18) and the angle emerges as a critical aspect. In relation to this recommendation, the teacher grabs the student's arm (see Picture B) and moves it into a different position than what the student has chosen himself, which could be interpreted as supplementing his verbal instructions. The teacher uses contrast as a pattern of variation when he compares how the actual act should be performed (both verbally, by saying "angle it more", and physically, by helping the student find the correct value of the angle with his hands). As soon as the teacher has done this he asks the student to "Angle it like tha:t" (line 20), and when the teacher says "that's right" (lines 20-21), he seems to be satisfied with the result, and the critical aspect angle has been ascribed its right value.

In line 26, Robin asks the teacher if the resulting weld does not get "very very thin" and thereby shows that he seeks confirmation that he understood, which the teacher gives. However, the teacher's response on line 27 ("it doesn't matter") indicates that this is not something the student needs to focus on. The student contrasts the thickness of the weld to a showed expectation that the weld should have been thicker. However, the teacher does not follow up this line. Hence, the thickness is dismissed as a critical aspect in this situation. Instead, a longer sequence follows in lines 29-35 during which the teacher actively tells Robin how to weld. Here, again, heat emerges as a critical aspect. The teacher emphasises this critical aspect by contrasting what is done to how it should be done. First, he tells Robin that he "need(s) to heat more back first", at the same time as he clarifies this by pulling his right arm backwards (Picture C), and then to "go forward" and "cut towards [...] with the flame". In line 29 the teacher confirms the student's welding by saying "like that yes" which implies that Robin does it right and that the critical aspect has adopted the right value in Robins welding act. Thereafter, a sequence of activities follows, which all culminates in the superior critical aspect angle. The teacher first asks Robin to "turn around" and to "(a)ngle it more" (uses contrasting to the actual act). During this whole sequence, the teacher is also actively giving positive feedback on Robin's actions, and in line 33 he says that if Robin finds it hard to "paddle around" then he can just "poke in it so that it might attach in the middle for you or it get less attached then". Here the teacher gives two alternatives, which both produce the right result. These alternatives are related to what is easier and harder to do. The sequence ends with the teacher praising Robin for letting welding take time "(b)ecause it takes time to weld" (line 35). Here time is emphasised as a critical aspect of welding. The teacher's feedback indicates that it already has the right value, so no pattern of variation is used. This whole sequence shows when the superior critical aspect- the angle - adopts the right value, other critical aspects (heat and time) come into the foreground.

Later, during the same session in the school workshop, Robin and his teacher are involved in a new teaching situation. This time the task is to weld together two short steel pipes (Situation 2). Before the next excerpt starts, the teacher has demonstrated welding while the student was watching.

\section{"But you know the pipe is turning" (Situation 2)}

As soon as the teacher (T) has finished welding and pushed up his protective goggles, Robin (S) turns to him and asks a question: 
the side watching. All critical aspects emerge together through fusion and the teacher acts as a "role model" in demonstrating the entire act of welding. As soon as the teacher stops his instruction, the student approaches the teacher on line 1 and makes a statement-here formulated as a question - that the teacher "add[s] the flame rather early" when he "spots". The student orients himself to finding out whether when you add the flame is a critical aspect. He notices that the flame is added early in this case. No pattern of variation is used and it is not visible from the interaction whether this is a critical aspect. However, it is clear that it is not a foregrounded critical aspect of the specific teaching situation, since the teacher does not elaborate on this interactional content. Instead, the teacher focuses on the angle as the general critical aspect throughout the example. Given the teacher's questioning response in line 2, the student repeats his question, upon which the teacher is positioned from lines 5-24 as the one with epistemic authority and who knows how to weld, by telling the student how to weld the two pipes together, while the student is positioned as the less skilled one who is learning.

The interesting thing about this example - and what distinguishes it from situation 1 -is that the teacher during his instruction refers to the earlier welding act and what was done then and puts it in relation to what is going to be done here and now. Hence, the teacher compares the two teaching situations to each other, by emphasising their similarities and differences. The comparison concerns the welded objects (a plate and a pipe) and how the angle and the movement of the tool are influenced by the task. When the teacher answers-in lines 5-6 and 8-he directly points out that the welding to be done now ("when you weld on a pipe") differs from the welding that was done before ("Before, you welded on a plate"). The shape of the material emerges as a critical aspect by the pattern of variation contrast, through which a pipe is compared to a metal plate. In these turns, the teacher emphasises the word "pipe" and uses the utterance "you know" (ju in Swedish) which in this specific case is used to seek for agreement (Aijmer 1996; Melander 2012) from the student (it underlines that the hearer already knows what is claimed).

The student also affirms the teacher's turns (lines 7 and 9) and in lines 10-14 the teacher then develops his instruction by focusing on the angle that should be "same" (as before) (the angle appears as a critical aspect and the pattern of variation used is generalisation: the teacher compares the previous welding angle to the current welding angle and states that it will be the same), but since "the pipe is turning" (note how he again uses "don't you"), one must also follow with the "right angle". Here, the critical aspect of the material is further clarified, in that it is evident that it is the shape of the material that is in focus when the previous situation is compared with the current one through the variation pattern contrasting - and it is also made explicit that the angle is the angle in relation to the rounded material-here is not the angle in relation to the heat or the body, as in the examples above, but in relation to the objects being welded together. The fact that the pipe is turning is not only something that the teacher emphasises by saying this, he also reinforces this by first making a turning, circular movement with his left hand (see Picture D-E), after which he says he "he has to follow" while he simultaneously makes a circular movement from left to right with his whole body. Here, the teacher repeats, with variation, the circular movement and again we have an example of an activity that is constituted not only by speech, but also by embodied semiotic resources, and their integrated use in interaction (see, for example, Goodwin 2000). The shape of the pipe emerges as a critical aspect that has an impact on the movement. How the movement follows the shape is made explicit through generalisation, in that the teacher shows this with the movement of his hand and body. 
As the teacher here refers to the previous lesson when they were welding on a plate, the welding that was executed then, and the specific content that was oriented to, are reactualised. This is thus an action and content that the teacher and the student are familiar with-something that is also made relevant in the example. In line 16, the teacher asks the student if he "follow[s]" and thus shows that he wants to know if the student has understood, and although the student responds affirmatively, the teacher continues his instruction in the next turn.

Here, the teacher approaches the pipes that should be welded with his body (Picture F-G) by showing the student how he should weld by again orienting to the angle that still should be "in the angle and then you follow and then you have to change the angle: o:f the nozzle as well". The angle is, again (as in the example above), the critical aspect that is in focus. The movement that must follow the shape of the pipe in order to keep the angle constant is however made explicit. Thus, a hierarchy between the critical aspects emerges and the example shows how the different critical aspects co-operate and contextualise each other in the act of welding. In line 24 the teacher says that he can show the student how the welding should be done whereby he takes position and begins to weld.

In the example, the teacher positions himself towards a selection of transient contiguous content and thus orients towards longitudinality. Longitudinal orientation-in this case taking the form of relating to what has been done previously, and how it shall be done-is also one of the resources used by participants to construct an activity such as "teaching" and "learning" (Martin and Sahlström 2010; Slotte-Lüttge, Pörn and Sahlström 2013).

Our last excerpt also refers to the second situation (welding together two pipes). At the start of the excerpt, the student has been welding for a while under the teacher's supervision when the teacher suddenly asks the student to stop welding for a moment: 


\section{“This angle that we talked about" (Situation 2)}
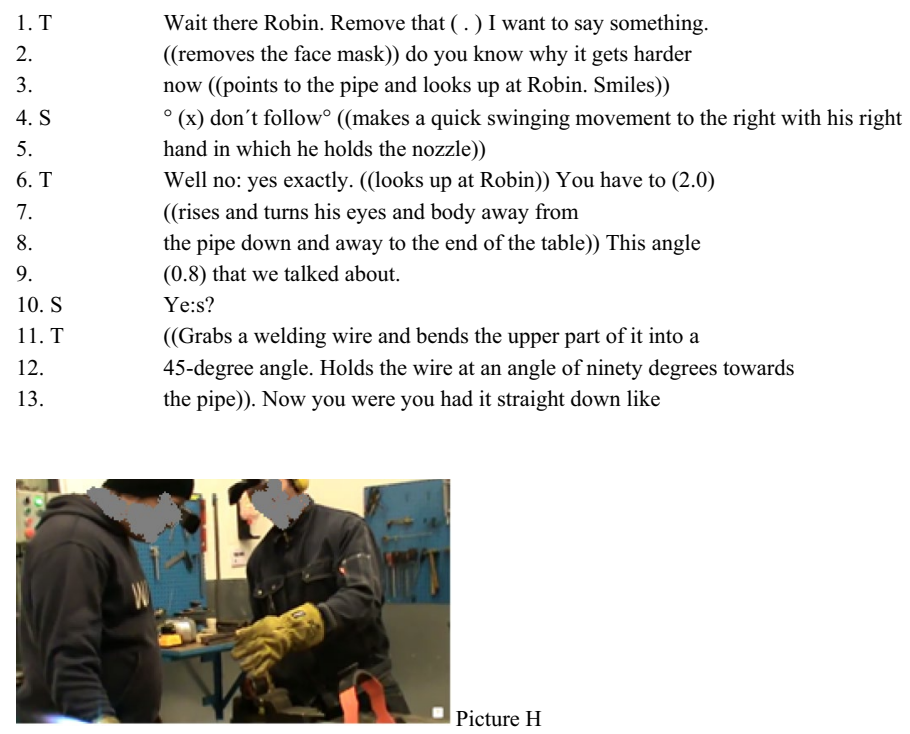

14. you have to meet up ( . ) more li:ke that there.

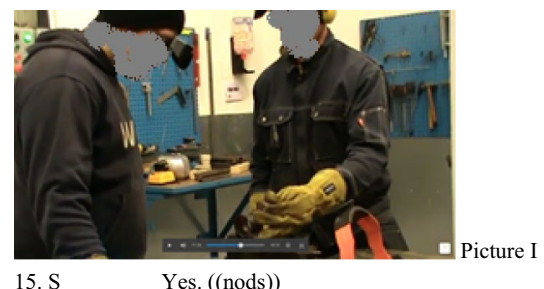

After the teacher has asked the student to stop welding for a moment, the teacher asked him if he knows "why it gets harder now". Here the whole situation 2 is contrasted to situation 1 (fusion), where the student is given the task of separating the critical aspect/s which makes the second situation harder than the first. The question indicates that the teacher has discerned that the student has some difficulties welding, which also is confirmed by the student who answers the question (an answer which is hard to interpret since the pupil talks rather quietly, which can indicate insecurity) at the same time as he makes a swinging movement with one of his hands. The pipe and its turning shape are separated by the student (line 4) as the critical aspects that mark the second situation (situation 2) in relation to situation 1. Furthermore, the question implies an explicit orientation to knowing something, and therefore also a shift to a teaching situation where the teacher is the one teaching and the student the one who is taught.

First, the teacher dismisses the student's answer on line 6 (possibly he did not expect a "correct" answer?) but he immediately corrects himself ("yes exactly"). Thereafter he again orients himself towards "the angle" that they "talked about" earlier (line 9). Again, the angle is highlighted as a critical aspect by the teacher and again he uses generalisation 
as a pattern of variation when he relates to something they have talked about earlier, emphasising what the angle should be like. This is another example of a longitudinal orientation that the teacher again raises as a topic of conversation (cf. example Slotte-Lüttge et al. 2013). In lines 11-14 the earlier instruction is again made the topic when the teacher bends the welding rod to illustrate the position the nozzle is supposed to be in in relation to the objects that are to be welded. The teacher separates the critical aspect the angle and uses generalisation as pattern of variation when using another material to demonstrate the angle of the nozzle (see Picture H-I). In relation to this, the teacher says "Now you were you had it straight down like you have to meet up (.) more li:ke that" in lines 13-14. The student recognises this in his next turn. Here, the teacher contrasts the actual act to how it should have been done. Hence, we have an example of a longitudinal orientation to an act and content in which semiotic resources are integrated and synchronised (speech, body and artefact).

\section{Discussion}

In this article, the learning process of welding in relation to welding on a plate (situation 1) and welding two pipes together (situation 2) has been analysed in detail, and the critical aspects that emerged in the interaction and how the actors oriented to them are summarised in Table 2.

The critical aspects in relation to welding that emerge in the teaching situation (the enacted OoL) are negotiated in the interaction between the teacher and the student, depending on the student's questions, actions and handling of the tools and material involved in the process of learning how to weld. When separating the critical aspects, the teacher uses the two situations to contrast and to generalise critical aspects between the situations. Accordingly, the teacher and the student jointly build up a common resource of experiences they can relate the parts and the whole to. The aspects vary and become increasingly complex and interwoven the more the teacher and the student interact on the OoL. In the first situation, fusion is used when the teacher acts as a role model; this is what Lo (2012) calls internal fusion. In the second situation, when the teacher and student have a common bank of experiences, external fusion is involved when the present situation is compared to another situation as a whole. Thereby the learning process also involves progression and the OoL in situation two is related to the OoL in situation one (compare Lo and Chik 2016). Furthermore, the teaching becomes increasingly subject specific as the teacher and the student build up more shared experience.

The angle (of the hand or tool) is the critical aspect which remains in the foreground in the teaching during the examples on the whole. In the interaction, other critical aspects are highlighted, both by the teacher and the student. When the teacher highlights other critical aspects he mostly relates them to the angle (e.g. the heat; the movement in relation to the material). However, when the student highlights other critical aspects, they are not always related to the angle. Sometimes the teacher elaborates on the critical aspects highlighted by the student and sometimes he dismisses them. When the critical aspects highlighted by the student are dismissed, or at least not further highlighted by the teacher, it is not clear if it is because they are not important (they are not critical aspects of welding), or if they could be critical aspects but the student needs to learn other things first. As in Asplund and Kilbrink (2018), we can see that no patterns of variation are used in relation to aspects that already have the right value in the teaching situations. 


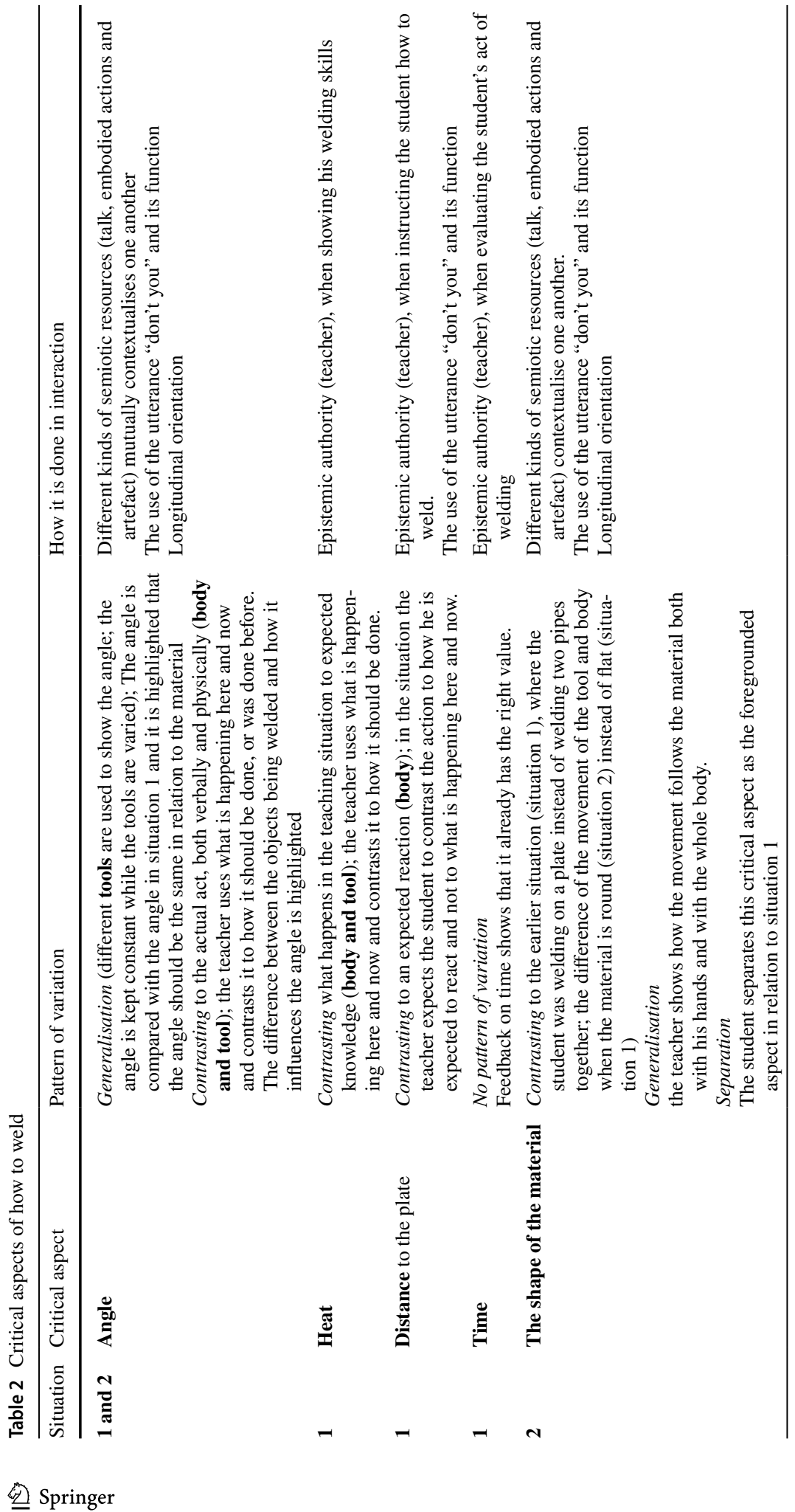




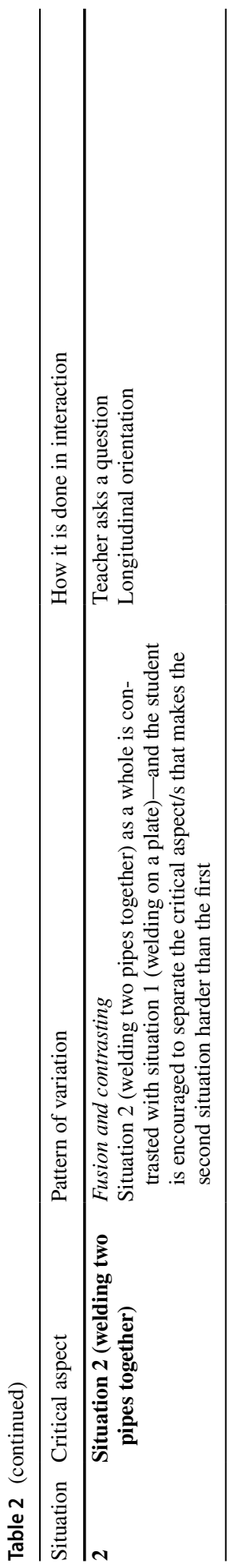


In our analyses, we have shown how the teacher and the student orient themselves to the activity as a learning and teaching situation in which the teacher teaches, and the student is to be taught and to learn. This is also the result of a joint effort; it is thus something that is done in interaction between teacher and student through their displayed participant orientation and situational and relational relevance (Slotte-Lüttge et al. 2013), where multiple semiotic resources are used simultaneously and integrated.

In the analyses we have also shown that parts of the second teaching situation are longitudinally established by the teacher and the student - and in many respects, this longitudinal orientation is explicitly progressively oriented (cf. Sahlström et al. 2010) in that what is being done is related to what has already been done, and also to what should be done. Thus the welding that the teacher and the student orient themselves to in the second analysed situation is related to the interaction on the welding that has already taken place, and the welding that should be done (see also Kilbrink and Asplund 2018).

Furthermore, we have been able to show that the learning and teaching which are made relevant in the studied teaching situations involve explicit orientation to learning content. In this orientation to the learning content, the teaching focus is alternated between the process as a whole, and details of the process of learning how to weld. In both the analysed situations, the teacher starts by modelling the whole process of welding. Then all the critical aspects are fused in the teacher's welding action. Thereafter the critical aspects are highlighted one by one in the teaching situation, as the student tries to weld under supervision (see Table 2). When separating the different critical aspects, the teacher mostly uses contrast to highlight how something should be done in relation to how it should not be done. These are processes that we have been able to describe in great detail by intertwining variation theory with a conversational analytic approach, and thus this article contributes to and deepens the works of Fillietaz (2011) and Sakai et al. (2014) and our own previous studies on learning to weld in school contexts (Asplund and Kilbrink 2018; Kilbrink and Asplund 2018).

\section{Conclusion}

This study concerns one teacher and one student in two different learning situations regarding how to weld, showing one specific example of teaching and learning how to weld. Hence, this study should not be seen as making general claims on teaching and learning how to weld. Rather, the study gives us insights in how a learning process in relation to the specific object of learning can be made in interaction and influenced by the participants in the interaction. Furthermore, in the results, we can see that learning how to weld is a complex process. The combination of frameworks that are used in this article sheds light on this complexity, and also facilitates an understanding of welding as an object of learning as such. Furthermore, the common understanding between teacher and student is part of this complex process and is negotiated in interaction and made visible in our close and detailed analysis. In this study, we can see the hierarchical relation between the critical aspects, where one (the angle) is superior in the teaching situation. In the complex process of learning how to weld, the intertwined movement between parts and the whole is oriented to in the interaction, thus making it, as well as aspects that are sometimes regarded as tacit, explicit. Learning processes and technical vocational objects of learning represent an under-researched area, and these frameworks can be used for studying more objects of learning in interaction to meet the need for more research. 
Open Access This article is distributed under the terms of the Creative Commons Attribution 4.0 International License (http://creativecommons.org/licenses/by/4.0/), which permits unrestricted use, distribution, and reproduction in any medium, provided you give appropriate credit to the original author(s) and the source, provide a link to the Creative Commons license, and indicate if changes were made.

\section{References}

Aijmer, K. (1996). Swedish modal particles in a contrastive perspective. Language Sciences, 18(1), $393-427$.

Asplund, S. B. (2016). Body talk: Moving beyond speech when analysing literature discussions. Language and Literacy, 18(3), 1-15.

Asplund, S-B., \& Kilbrink, N. (2018). Learning how (and how not) to weld: Vocational learning in technical vocational education. Scandinavian Journal of Educational Research, 62(1), 1-16.

Berglund, I. (2009). Byggarbetsplatsen som skola - eller skolan som byggarbetsplats?: En studie av byggnadsarbetarens yrkesutbildning [Construction site as School - or school as construction site?: A study of vocational education and training for workers within building and construction]. Doctoral thesis, Institutionen för didaktik och pedagogiskt arbete, No. 2009:4. Stockholm University, Stockholm.

Björkholm, E. (2015). Konstruktioner som fungerar: En studie av teknikkunnande i de tidiga skolåren. Dissertation, Stockholm: Stockholm University.

Bjurulf, V. (2008). Teknikämnets gestaltningar: En studie av lärares arbete med skolämnet teknik. (Karlstad University Studies, No. 2008:29). Dissertation, Karlstad: Karlstad University.

Chan, S., \& Leijten, F. (2012). Using feedback strategies to improve peer-learning in welding. International Journal of Training Research, 10(1), 23-29.

Drew, P., \& Heritage, J. (2006). Editors' introduction. In P. Drew \& J. Heritage (Eds.), Conversation analysis (Vol. 1, pp. xxi-xxxvii). London: Sage.

Emanuelsson, J., \& Sahlström, F. (2008). The price of participation. Teacher control versus student participation in classroom interaction. Scandinavian Journal of Educational Research, 52(2), 205-223.

Filliettaz, L. (2011). Collective guidance at work: A resource for apprentices? Journal of Vocational Education \& Training, 63(3), 485-504.

Goodwin, C. (2000). Action and embodiment within situated human interaction. Journal of Pragmatics, 32(10), 1489-1522.

Goodwin, C. (2006). Human sociality as mutual orientation in a rich interactive environment: Multimodal utterances and pointing in aphasia. In N. J. Enfield \& S. C. Levinson (Eds.), Roots of human sociality: Culture, cognition and interaction (pp. 97-125). Oxford/New York: Berg Publishers.

Heath, C. (1997). The analysis of activities in face to face interaction using video. In D. Silverman (Ed.), Qualitative research. Theory, method and practice. London: Sage Publications Ltd.

Heritage, J., \& Raymond, G. (2005). The terms of agreement: Indexing epistemic authority and subordination in talk-in-interaction. Social Psychology Quarterly, 68(1), 15-38.

Hutchby, I., \& Wooffitt, R. (2008). Conversation analysis. Cambridge: Polity Press.

Kilbrink, N. (2013). Lära för framtiden: Transfer i teknisk yrkesutbildning [Learning for the future: Transfer in technical vocational education, in Swedish] (Karlstad University studies, No. 2013:4). Karlstad: Karlstad University.

Kilbrink N. (2018). Technical vocational education: From dualistic to pluralistic thinking. In: M. de Vries (Ed.), Handbook of technology education (pp. 193-204). Springer International Handbooks of Education. Springer, Cham. https://doi.org/10.1007/978-3-319-44687-5_22.

Kilbrink, N., \& Asplund, S-B. (2018). Learning to weld in technical vocational education: the first cycle of an action-oriented study. In PATT36 international conference: Research and practice in technology education: Perspectives on human capacity and development, 18-21 June 2018. Athlone, Ireland.

Kilbrink, N., Bjurulf, V., Blomberg, I., Heidkamp, A., \& Hollstein, A-C. (2014). Learning a specific content in technology education: Learning Study as collaborative method in Swedish preschool class using hands-on material. International Journal of Technology \& Design Education, 4(3), 241-259.

Lo, M. L. (2012). Variation theory and the improvement of teaching and learning. Göteborg: Acta universitatis Gothoburgensis.

Lo, M. L., \& Chik, P. P. M. (2016). Two horizons of fusion. Scandinavian Journal of Educational Research, 60(3), 296-308.

Martin, C., \& Sahlström, F. (2010). Learning as longitudinal interactional change: From other-repair to selfrepair in physiotherapy treatment. Discourse Processes, 47(8), 668-697. 
Marton, F., \& Booth, S. (1997). Learning and awareness. New Jersey, Mahwah: Lawrence Erlbaum Associates Inc.

Marton, F., \& Tsui, A. B. (Eds.). (2004). Classroom discourse and the space of learning. Mahwah, N.J: Lawrence Erlbaum.

Melander, H. (2012). Transformations of knowledge within a peer group. Knowing and learning in interaction. Learning, Culture and Social Interaction, 1(3), 232-248.

Mondada, L. (2006). Video recording as the reflexive preservation and configuration of phenomenal features for analysis. In H. Knoblauch, J. Raab, H.-G. Soeffner, \& B. Schnettler (Eds.), Video analysis (pp. 51-68). Bern: Lang.

Ochs, E., Schegloff, E. A., \& Thompson, S. A. (Eds.). (1996). Interaction and grammar. Cambridge: Cambridge University Press.

Pahl, J. (2014). Vocational education research: Research on vocational pedagogy, vocational discipline and vocational didactics. In Z. Zhau \& F. Rauner (Eds.), Areas of vocational education research, new frontiers of educational research (pp. 17-43). Berlin Heidelberg: Springer-Verlag.

Sacks, H., Schegloff, E., \& Jefferson, G. (1974). A simplest systematics for the organization of turn-taking for conversation. Language, 50, 696-753.

Sahlström, F. (2009). Editorial. Scandinavian Journal of Educational Research, 53(2), 103-111.

Sahlström, F. (2011). Learning as social action. In J. K. Hall, J. Hellermann, \& S. P. Doehler (Eds.), L2 interactional competence and development. Bristol: Multilingual Matters.

Sahlström, F., Hummelstedt, I., Forsman, L., Pörn, M. \& Slotte-Lüttge, A. (2010) Samma innehåll olika sammanhang: mikro-longitudinellt lärande i sjuåringars vardag. In C.Lindholm \& J. Lindström (Eds.), Språk och interaktion 2 (pp. 1-22).

Sakai, S., Korenaga, R., Mizukawa, Y., \& Igarashi, M. (2014). Envisioning the plan in interaction: Configuring pipes during a plumbers' meeting. In M. Nevile, P. Haddington, T. Heinemann, \& M. Rauniomaa (Eds.), Interacting with objects: Language, materiality, and social activity (pp. 339-356). Amsterdam/ Philadelphia: John Benjamins Publishing Company.

Schegloff, E. A. (1996). Confirming allusion: Toward an empirical account of action. The American Journal of Sociology, 102, 161-216.

Schegloff, E. A. (2006). Interaction. The infrastructure for social institutions, the natural ecological niche for language, and the arena in which culture is enacted. In N. J. Enfield \& S. C. Levinson (Eds.), Roots of human sociality. Culture cognition and interaction (pp. 70-98). Oxford: Berg.

Schegloff, E. A. (2007). Sequence organization in interaction. A primer in conversation analysis 1. Cambridge: Cambridge University Press.

Slotte-Lüttge, A., Pörn, M., \& Sahlström, F. (2013). Learning how to be a tähti: A case study of language development in everyday situations of a 7-year-old multilingual Finnish child. International Journal of Bilingualism, 17(2), 153-173.

Streeck, J., Goodwin, C., \& LeBaron, C. (Eds.). (2011). Embodied interaction: Language and body in the material world. Cambridge: Cambridge University Press.

Tsui, A. B. M. (2004). The shared space of learning. In F. Marton \& A. B. M. Tsui (Eds.), Classroom discourse and the space of learning (pp. 3-40). Mahwah, NJ: Erlbaum.

von Schantz Lundgren, I., Lundgren, M., \& Svensson, V. (2013). Learning study i gymnasial yrkesutbildning: En fallstudie från ett hantverksprogram. Nordic Journal of Vocational Education and Training, 3(4), 1-16. 